\title{
INFLUENCE OF SHIELDING GAS FLOW RATE ON PROPERTIES OF STEEL S960QL WELDED JOINT
}

\author{
'Štěpán JEŽEK, ²Jakub HORVÁTH, 'Ladislav KOLAŘíK, ${ }^{2}$ Jiří JANOVEC, ${ }^{1}$ Marie KOLAŔíKOVÁ \\ ${ }^{1}$ Department of Manufacturing Technology, Faculty of Mechanical Engineering, Czech Technical University \\ in Prague, Technická 4, Praha 6, Czech Republic, EU, stepan.jezek@fs.cvut.cz, ladislav.kolarik@fs.cvut.cz, \\ marie.kolarikova@fs.cvut.cz \\ ${ }^{2}$ Department of Material Engineering, Faculty of Mechanical Engineering, Czech Technical University in \\ Prague, Technická 4, Praha 6, Czech Republic, EU, Jakub.horvath@fs.cvut.cz, iiri.janove@fs.cvut.cz
}

https://doi.org/10.37904/metal.2020.3532

\begin{abstract}
The experiment aimed on influence of shielding gas flow rate on properties of single $\mathrm{V}$ groove butt weld of high strength ultra-fine grained steel S960QL (XABO 960) and filler material G 896 M21 Mn4Ni2CrMo (X90) is described in this article. The steel $\mathrm{S} 960 \mathrm{QL}$ is sensitive to presence of hydrogen in material structure, in exceed of maximal recommended content $(<5 \mathrm{ml} / 100 \mathrm{~g})$ the cold cracking may take place. During the experiment specimen 1 with reduced flow rate 5 I.min-1 and specimen 2 with recommended flow rate 14I.min-1 was welded. The active shielding gas Corgon with the $82 \% \mathrm{Ar}$ and $18 \% \mathrm{CO} 2$ ratio was used. Flow rate of shielding gas has a noticeable influence on properties of welded joint. Because of specimen 1 reduced flow rate the full penetration was not achieved, chemical composition evaluation of weld metal shows fewer deoxidizing elements $(\mathrm{Si}, \mathrm{Mn}, \mathrm{Ti})$ and increased hydrogen contents $(\approx 18 \mathrm{ml} / 100 \mathrm{~g})$ as a result of chemical reaction between weld metal and air during welding. The increased hydrogen content, type of base metal and lack of penetration were the reasons of fracture of the specimen 1. Cold cracking was confirmed by hydrogen content measurement and by fracture surface evaluation by optical and electron microscopy. The porosity, fish eyes and cleavage facets typical for brittle fracture was found by microscopy. The high-quality weld with low content of hydrogen can be obtained with the recommended shielding gas flow rate, the flow rate adjustment is one of method how to avoid cold cracking of welds.
\end{abstract}

Keywords: Hydrogen induced cracking, cold cracking, shielding gas, S960QL, MAG

\section{INTRODUCTION}

The high strength structure steels (e.g. S960QL) are very cold cracking susceptible. It is easily possible to reach the cold cracking material conditions after a welding process - obtaining of a hydrogen sensitive material structure, exceeding of maximum recommended hydrogen content in material structure and a residual tension stress. The brittle trans- granular fracture is typical for the cold cracking. [1-3]

One of the influence on the cold cracking susceptibility of high strength steel welds has microstructural constituents and chemical composition, Yi and col. [4] found out, the that acicular ferrite produced the greatest resistance to cold cracking and the retained austenite had no effect on the cold cracking susceptibility at a low preheating temperature. Alloying elements for nucleating acicular ferrite, such as $\mathrm{Ti}, \mathrm{Al}$, and $\mathrm{V}$, are required for proper austenite grain size. Kim and col. [5] proved influence of Ni content in weld metal on cold crack susceptibility. The $1.5 \% \mathrm{Ni}$ wire resulted in a weld microstructure with a lower grain boundary ferrite content associated with an increased proportion of acicular ferrite. According to Weglowski and col. [6] the heat cycle and preheating temperature decided of tendency to cold cracking and the optimal preheating temperature was $100^{\circ} \mathrm{C}$. The composition of the shielding gas has a influence on the cold cracking, based on the Chen and col. 
[7] the shielding gas mixture can exert a major influence on weld metal transverse cold cracking behavior. In his research welds with preheat temperatures higher than $40{ }^{\circ} \mathrm{C}$ no weld metal cracking was observed using a shielding gas consisting of argon with $20 \%$ carbon dioxide. In contrast, the no-crack condition was not achieved for a shielding gas consisting of argon and $5 \%$ carbon dioxide for preheat temperatures lower than $100{ }^{\circ} \mathrm{C}$. The content of the Hydrogen in weld metal is critical, Pitrun and col. [8] published that the research results indicate that the weld metal susceptibility to cold cracking correlates with diffusible hydrogen content. It was found that, without preheat weld deposits $(<5 \mathrm{ml} / 100 \mathrm{~g}$ ) did not crack whereas all those weld metals (> $5 \mathrm{ml} / 100 \mathrm{~g}$ ) exhibited cold cracking. The researchers use mostly the $\mathrm{Y}$ groove Tekken test $[4,6]$ or the Gapped bead-on-plate test(G-BOP) $[5,[8]$ for an evaluation of the welds cold cracking susceptibility.

The material structure sensitive on hydrogen effect is the quenched structure - martensite. The martensite or the martensite-bainite material structure is obtained in the weld metal, heat affected zone and the base metal of S960QL steel welds in a combination with the filler material G $896 \mathrm{M} 21 \mathrm{Mn} 4 \mathrm{Ni2CrMo}$. The content of the hydrogen in material structure can be critically increased by a base metal manufacturing, during a technological operation or by an environment exposure during product utilization. The high level of residual stress occurs in the material after a welding process. This tenseness has a significant influence on the cold cracking. [4-6]

\section{EXPERIMENT}

The aim of the experiment was to evaluate an influence of the shielding gas flow rate on properties of the welded joint and the cold cracking occurrence. The GMAW welding method was used. The single $\mathrm{V}$ groove butt weld with the opening angle $60^{\circ}$ and the root gap $0.8 \mathrm{~mm}$. The joint preparation followed EN ISO 9692-1 recommendations. The plate thickness was $5 \mathrm{~mm}$.

Two specimens were used for the evaluation of the flow rate influence. Both specimens were welded with the same welding process parameters the only difference was in the shielding gas flow rate. The recommended flow rate of the shielding gas I [I. $\left.\mathrm{min}^{-1}\right]$ can be determine according to the formula I $=10 \cdot \mathrm{d}+2\left[\mathrm{I} \cdot \mathrm{min}^{-1}\right]$, where $\mathrm{d}$ $[\mathrm{mm}]$ is the filler material wire diameter. The recommended value of the shielding gas flow rate was $14 \mathrm{I} \cdot \mathrm{min}^{-1}$ during the welding of the specimen 1 the flow rate was reduced to $5 \mathrm{I} \cdot \mathrm{min}^{-1}$. The active shielding gas Corgon (EN ISO 14175- M21- ArC- 18) with the $82 \% \mathrm{Ar}$ and $18 \% \mathrm{CO}_{2}$ mixing ratio was used.

The welding process parameters are in Table 1. The t8/5 was calculated in the WeldCalc (SSAB) software. The values in the Table 1 and the thermal efficiency $0.8[/]$ was used for the calculation. The welding was performed without a preheating of the material the initial material temperature was equal to a laboratory temperature $\left(\approx 22^{\circ} \mathrm{C}\right)$.

Table 1 Welding process parameters

\begin{tabular}{|c|c|c|c|c|c|c|}
\hline $\begin{array}{c}\text { Specimen } \\
\text { No. }\end{array}$ & $\begin{array}{c}\text { Current } \\
(\mathbf{A})\end{array}$ & $\begin{array}{c}\text { Voltage } \\
(\mathbf{V})\end{array}$ & $\begin{array}{c}\text { Welding } \\
\mathbf{s p e e d} \\
\left(\mathbf{c m} \cdot \mathbf{m i n}^{-1}\right)\end{array}$ & $\begin{array}{c}\text { Heat input } \\
\left(\mathbf{k J} \cdot \mathbf{m m}^{-1}\right)\end{array}$ & $\begin{array}{c}\text { Flow rate } \\
\left(\mathbf{I} \cdot \mathbf{m i n}^{-1}\right)\end{array}$ & $\begin{array}{c}\text { t/5/5 } \\
(\mathbf{s})\end{array}$ \\
\hline 1 & 170 & 20 & 30 & 0.54 & 5 & 11.9 \\
\hline 2 & 170 & 20 & 30 & 0.54 & 14 & 11.9 \\
\hline
\end{tabular}

The macrostructure evaluation, the visual testing according to EN ISO 17637, the X-Ray fluorescent spectroscopy analysis of the weld metal chemical composition, the thermal conductivity detection method for an assessment of the hydrogen content in the weld metal and both the optical and the electron microscopy on the surface of the fracture was performed on the specimens.

\section{MATERIAL}

The ultra-fine grained high strength steel S960QL (XABO 960) according to the EN 10025-6 with dimensions $350 \times 150 \times 5 \mathrm{~mm}$ was used as a base metal of the specimens. The filler material G $896 \mathrm{M} 21 \mathrm{Mn} 4 \mathrm{Ni2} \mathrm{CrMo}$ 
(Böhler Union X90) according to the EN ISO 16834-A with a wire diameter $1.2 \mathrm{~mm}$ was used for the welding. The mechanical properties of both materials are in Table 2, the chemical compositions are in Table 3. Both mechanical properties and chemical composition was obtained in inspection certificate 3.1 according to EN 10204

Table 2 Mechanical properties

\begin{tabular}{|c|c|c|c|c|}
\hline Material & $\begin{array}{c}\text { Yield strength } \mathbf{R}_{\mathbf{p}, \mathbf{2}} \\
\left(\mathbf{N} \cdot \mathbf{m m}^{-\mathbf{2}}\right)\end{array}$ & $\begin{array}{c}\text { Tensile strength } \mathbf{R}_{\mathbf{m}} \\
\left(\mathbf{N} \cdot \mathbf{m m}^{-2}\right)\end{array}$ & $\begin{array}{c}\text { Elongation A5 } \\
(\%)\end{array}$ & $\begin{array}{c}\text { Impact energy } \\
(\mathbf{J})\end{array}$ \\
\hline XABO 960 & 1033 & 1055 & 15 & $40\left(-40^{\circ} \mathrm{C}\right)$ \\
\hline Union X90 & $\geq 890$ & $950-1180$ & $\geq 15$ & $47\left(-60^{\circ} \mathrm{C}\right)$ \\
\hline
\end{tabular}

Table 3 Chemical composition (wt\%)

\begin{tabular}{|c|c|c|c|c|c|c|c|c|c|c|c|c|}
\hline Material & $\mathbf{C}$ & $\mathbf{S i}$ & $\mathbf{M n}$ & $\mathbf{P}$ & $\mathbf{S}$ & $\mathbf{C r}$ & $\mathbf{M o}$ & $\mathbf{N i}$ & $\mathbf{V}$ & $\mathbf{T i}$ & $\mathbf{A l}$ & $\mathbf{N b}$ \\
\hline XABO 960 & 0.17 & 0.22 & 1.24 & 0.009 & 0.001 & 0.21 & 0.597 & 0.05 & 0.04 & 0.03 & 0.051 & 0.015 \\
\hline Union X90 & 0.11 & 0.77 & 1.79 & 0.01 & 0.01 & 0.35 & 0.59 & 2.20 & $<0.01$ & 0.07 & $<0.01$ & \\
\hline
\end{tabular}

\section{EQUIPMENT}

The optical microscope Nikon SMZ 1500 was used for the macroscopy evaluation, the manual Energy Dispersive X-ray Fluorescence spectrometer Vanta Element was used for the weld metal chemical composition evaluation, the Bruker elements Galileo G8 OHN was used for the evaluation of hydrogen content, the optical microscope Nikon SMZ 1500 and the scanning electron microscope Jeol JSM-7600F was used for evaluation of fracture surface.

\section{RESULTS}

\subsection{Visual testing}

The visual testing was performed in accordance with the standard EN ISO 17637 and evaluated in accordance with the standard EN ISO 5817 in the quality level C.

The longitudinal crack (imperfection No. 101 according to EN ISO 6520-1) in the center of the weld of the specimen 1 occurred after cooling down see the Figure 1 (left). During the visual testing of the root the lack of penetration (imperfection No. 4021 according to EN ISO 6520-1) was found out, see the Figure 1 (right). Imperfections are critical, for the selected quality level $\mathrm{C}$ are these imperfections impermissible. The result of the visual testing of the specimen 2 was accessible - without imperfections.


Figure 1 Specimen 1 - The longitudinal crack and the lack of penetration 


\subsection{Weld macrostructure evaluation}

The cross section was polished and afterwards etched with a Nital $5 \%$. The macrostructures of both specimens are in the Figure 2. The lack of penetration with the depth $0.7 \mathrm{~mm}$, which was recognized during visual testing and the porosity caused by reduced flow rate of shielding gas is clearly visible in the picture of specimen 1 . The cross section of specimen 2 confirmed the visual testing result.
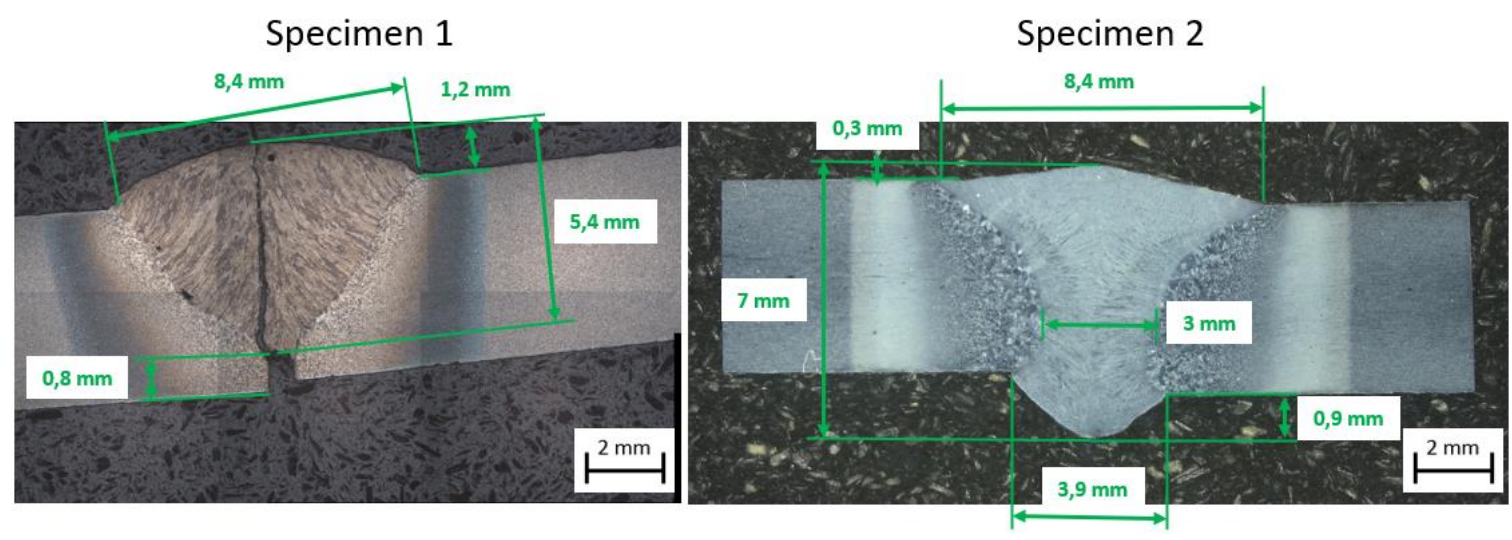

Figure 2 Cross sections of the specimen $1\left(5 \mathrm{I} \cdot \mathrm{min}^{-1}\right)$ and specimen $2\left(14 \mathrm{I} \cdot \mathrm{min}^{-1}\right)$

The shielding atmosphere flow rate had a significant influence on an amount of the heat in the weld pool and in consequence of it on the final appearance, penetration and reached quality of the weld, based on comparison of the cross sections. The weld seam has a deeper penetration it is narrower and has fewer excess of weld metal with the use of the higher flow rate.

\subsection{X-Ray fluorescent spectroscopy analysis}

The aim of the X-Ray fluorescent spectroscopy analysis was the evaluation of the flow rate influence on the weld metal chemical composition. The chemical compositions of the specimens weld metal are in the Table 4.

Table 4 Chemical composition of the weld metals (wt\%)

\begin{tabular}{|c|c|c|c|c|c|c|c|c|c|c|c|}
\hline Specimen No. & $\mathbf{S i}$ & $\mathbf{M n}$ & $\mathbf{P}$ & $\mathbf{S}$ & $\mathbf{C r}$ & $\mathbf{M o}$ & $\mathbf{N i}$ & $\mathbf{V}$ & $\mathbf{T i}$ & $\mathbf{A l}$ & $\mathbf{N b}$ \\
\hline 1 & 0.22 & 1.24 & 0.009 & - & 0.29 & 0.59 & 1.53 & 0.018 & 0.019 & 0.017 & 0.02 \\
\hline 2 & 0.77 & 1.79 & 0.01 & - & 0.25 & 0.57 & 1.56 & 0.008 & 0.041 & 0.015 & 0.0 \\
\hline
\end{tabular}

The content of the deoxidation elements $(\mathrm{Si}, \mathrm{Mn}, \mathrm{Ti})$ is reduced in the specimen 1 as a effect of the insufficient joint protection and a reactions between weld pool and the air gases - formation of the $\mathrm{SiO}_{2}, \mathrm{TiO}_{2}$ and $\mathrm{MnO}$ in form of a slag.

\subsection{Thermal conductivity detection method}

For evaluation of the hydrogen content the thermal conductivity detection method was used. The obtained contents of the hydrogen in the specimens are in the Table 5 . The sample of the weld metal with the weight lower than $0.4 \mathrm{~g}$ was necessary for this method.

Table 5 Hydrogen content in weld metal

\begin{tabular}{|c|c|c|c|}
\hline Specimen No. & Sample weight $(\mathbf{g})$ & $\mathbf{H}_{\mathbf{2}}(\mathbf{p p m})$ & $\mathbf{H}_{\mathbf{2}}(\mathbf{m l} / \mathbf{1 0 0 g})$ \\
\hline 1 & 0.284 & 16.2 & 18 \\
\hline 2 & 0.3453 & 1.5 & 1.7 \\
\hline
\end{tabular}


The shielding gas flow rate had obvious influence on the hydrogen content in weld metal. The weld metal of the specimen 1 contents more than 10 times as much hydrogen as the weld metal of the specimen 2.

\subsection{Optical microscopy evaluation of fracture surface}

The magnified fracture surface is in the Figure 2. In the Figure 2 left is visible porosity - imperfection 2013 according to EN ISO 6520-1. The porosity size exceeds the standard EN ISO 5817 quality level C allowance limit. In Figure 3 right are visible fish eyes, lack of penetration and cleavage facet.
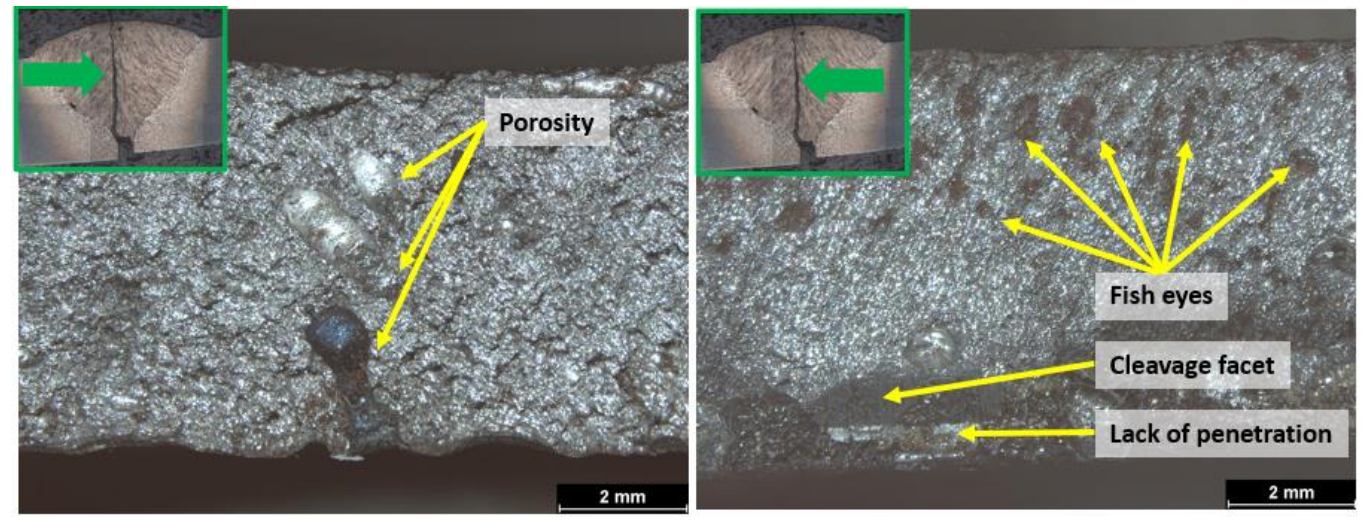

Figure 3 Specimen 1 - Fracture surface (Optical microscope)

The presence of the porosity and the fish eyes confirms the high content of gases in the weld pool due to reduced shielding atmosphere flow rate during welding. Cleavage facet from lack of penetration shows the location of crack initiation.

\subsection{Scanning electron microscopy evaluation of fracture surface}

The magnified fracture surface is in Figure 4. In Figure 4 left it is visible the detail of the cleavage facet, typical for brittle transgranual fracture and cold cracking. In Figure $\mathbf{4}$ right regular micro porosity can be seen, it confirms the result of optical microscopy result.

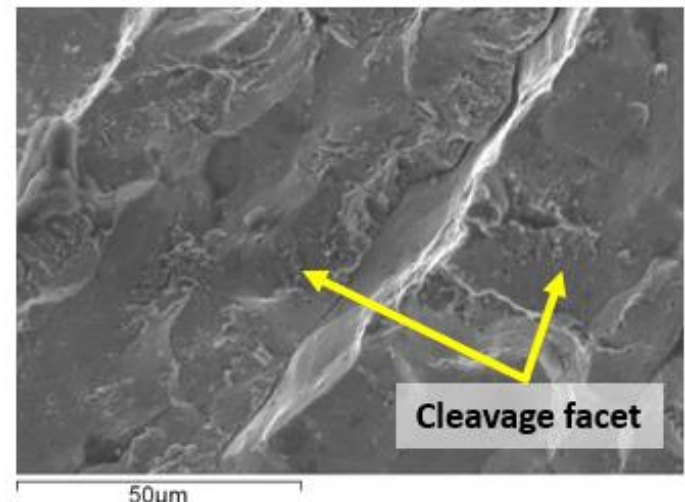

Figure 4 Specimen 1 - Fracture surface (electron microscope)

\section{DISCUSION}

The cold cracking occurrence is one of a difficulty due to welding of the high strength steels. The cold cracking susceptibility can be influenced by the chemical composition and the material structure, but the change has in consequences effect on material strength, as confirmed $\mathrm{Yi}$ and col. [4]. The cold cracking took place As a 
result of high hydrogen content in weld metal of specimen $1(18 \mathrm{ml} / 100 \mathrm{~g})$, the measured content confirms the conclusions of Pitrun and col. [8]. The preheating temperature and thermal cycle during welding influences the hydrogen content in the welded joint, according to Welglowski and col. [6]. The preheating is for the S960QL steel recommended from $8 \mathrm{~mm}$ of a plate thickness [2,3].

The shielding gas flow rate had the significant influence on the weld pool shape and quality and strength of the joint. The performed macroscopy evaluation corresponds with the research performed by Chen and col. [7]. The shielding gas flow rate influenced the chemical composition of the weld metal.

The cold crack susceptibility of the S960QL welded joint is influenced by a filler material strength selection. In combination with the filler material with a lower yield strength (e.g. G $694 \mathrm{M} \mathrm{Mn3Ni1CrMo)} \mathrm{the} \mathrm{ductility} \mathrm{of} \mathrm{weld}$ metal is increased but the strength is reduced $[2,3]$.

\section{CONCLUSION}

The influence of the shielding gas flow rate on the properties of the S960QL welded joint was investigated.

- The shielding gas flow rate influences the weld pool shape and both quality and strength of the welded joint

- $\quad$ The shielding flow rate influences the chemical composition of the weld metal

- The shielding flow rate influences the hydrogen content in the weld metal by reduction to $5 \mathrm{I} \cdot \mathrm{min}-1$ the hydrogen content grows up to $18 \mathrm{ml} / 100 \mathrm{~g}$. This content exceeds recommendation $<5 \mathrm{ml} / 100 \mathrm{~g}$

- The cold crack took place by reduction of flow rate. The microscopy confirmed fish eyes and brittle transgranual fracture, typical for cold cracking. The lack of penetration was location of crack initiation.

- It is necessary to fulfill the thermal cycle, flow rate and preheating temperature recommendations of the steel producers for quality welded joint achievement

\section{ACKNOWLEDGEMENTS}

\section{The research was supported by project SGS19/163/OKH2/3T/12.}

\section{REFERENCES}

[1] JANOVEC, J., MACEK, K., ZUNA, P. Fyzikální metalurgie. Praha: ČVUT, 2004.

[2] KLEIN, M., SONNLEITNER, M., STIASZNY, P. Alform x-treme innovation. Linz: Voestalpine Stahl GmbH, 2012.

[3] STEMNE, D., NARSTRÖM, T., HRNJEZ, B. Welding handbook: a guide to better welding of Hardox and Weldox. 1. ed. Oxelösund: SSAB, 2010.

[4] YI, H.J., LEE, Y.L., KIM, J.Y., KANG, S.S.. Effect of microstructure and chemical composition on cold crack susceptibility of high-strength weld metal. Journal of Mechanical Science and Technology [online]. 2006, vol. 25, no. 9, pp. 2185-2193.

[5] KIM, J.H. Effect of Weld Metal Microstructures on Cold Crack Susceptibility of FCAW Weld Meta. Metals and Materials International . 2008, vol. 14, no. 2, pp. 239-245.

[6] WĘGLOWSKI, M., ZEMAN M. Prevention of cold cracking in ultra-high strength steel Weldox 1300. Archives of Civil and Mechanical Engineering [online]. 2013, vol. 14, no. 3, pp. 417-424.

[7] CHEN, L., DUNNE, D., DAVIDSON, L. Use of the gapped bead-on-plate test to investigate hydrogen induced cracking of flux cored arc welds of a quenched and tempered steel. Australasian Welding Journal. 2014, vol. 59, no. 4, pp. 34-48.

[8] PITRUN, M. NOLAN, D. Susceptibility of Low Strength Rutile Flux-Cored Weld Metal to Hydrogen Assisted Cold Cracking. Welding in the World. 2020, vol. 50, no. 5-6, pp. 6-17. 